\title{
Assédio Moral em Estudantes Trabalhadores e sua Relação com o Bem-Estar no Trabalho
}

\author{
Alessandra Rodrigues Jacoby \\ Faculdades Integradas de Taquara (FACCAT) \\ Janine Kieling Monteiro \\ Universidade do Rio dos Sinos (UNISINOS)
}

\begin{abstract}
RESUMO
Este trabalho tem o intuito de investigar o assédio moral e as possíveis relações com o bem-estar no trabalho. Foram aplicados o Questionário Biosociodemográfico e Laboral, o Questionário de Atos Negativos - QAN e as Medidas de Bem-estar no Trabalho em 457 acadêmicos de graduação. Os resultados mostraram que há relação entre o assédio moral e as medidas de bem-estar no trabalho $(\mathrm{p}<0,05)$, indicando que a presença da violência psicológica causa uma diminuição no bem-estar laboral. $\mathrm{Na}$ análise de regressão linear, alguns atos negativos no trabalho foram preditores de duas dimensões das medidas de bem estar no trabalho. Estes resultados sugerem que a ocorrência de assédio moral está associada a menor satisfação e comprometimento no trabalho.
\end{abstract}

Palavras-chave: Assédio moral; trabalho; violência; saúde; bem-estar.

\begin{abstract}
Mobbing in student workers and their relationship to well-being at work

This study aims to investigate mobbing and possible relationships with well-being at work. We applied the Biosociodemográfico and Labour Questionnaire, the Negative Acts Questionnaire - QAN and Measures of Well-being at Work in 457 academic degree. The results showed no relationship between mobbing and measures of well-being at work $(\mathrm{p}<0.05)$, indicating that the presence of psychological violence causes a decrease in welfare work. In linear regression analysis, some negative acts at work were predictive of two-dimensional measures of well-being at work. These results suggest that the occurrence of mobbing is associated with less satisfaction and commitment at work.
\end{abstract}

Keywords: Mobbing; labor; violence; health; well-being.

O mundo do trabalho na atualidade é marcado pelo aumento da exploração, desregulamentação, flexibilização e precarização do trabalho, acompanhado do desemprego estrutural (Antunes, 2009). As novas formas de gestão, que surgem nesse contexto, priorizam a intensificação do trabalho, a avaliação individual de desempenho, focada em resultados e pautada em competições (Silva, Oliveira \& Zambroni-de-Souza, 2011). Essas questões têm impacto direto nas relações sócio-profissionais, bem como na saúde e bem-estar do trabalhador (Amazaray, 2010). O qual vive em constante ameaça: ficar sem emprego, seu trabalho ser terceirizado, receber a metade do salário, não ter a qualificação suficiente (Martins e cols., 2010; Monteiro, 2010). Além disso, o trabalhador precisa mostrar que é produtivo a qualquer custo (Eberle, Soboll \& Horst, 2010; Martins e cols., 2010), nem que para isto precise viver em um clima de medo e num ambiente hostil, se acos- tumando a isso por meio da banalização do mal (Dejours, 2001), colocando em risco a sua saúde e o bem-estar laboral.

As relações sócio profissionais são conceituadas como os modos de gestão do trabalho, a forma de comunicação e de interação profissional existente no contexto laboral (Mendes 2007a). Conflitos são inerentes às relações de trabalho, porém podem ser construtivos quando existe uma margem de negociação entre as partes. Para isso necessita que a organização do trabatho tenha alguma flexibilidade, que as condições físicas de trabalho sejam satisfatórias e que relações sócio profissionais sejam abertas ao diálogo e éticas. Por outro lado, quando os conflitos no trabalho não são negociáveis eles são fonte de sofrimento. A evolução, frequência e características desses conflitos podem, com o passar do tempo, traduzir-se em comportamentos agressivos, em violência e em práticas de assédio moral 
no trabalho, produzindo consequências danosas à saúde do trabalhador (Mendes, 2007b). Quando os atos negativos acabam se tornando ações sistemáticas e persistentes, podem se transformar em assédio moral (Eberle, Soboll \& Horst, 2010; Monteiro \& Machado, 2010).

Por outro lado, com o advento da Psicologia Positiva, tem crescido o interesse por estudos que buscam avaliar o bem-estar no trabalho. O bem-estar no trabalho está centrado na medida positiva de vários aspectos do trabalho: afetivos, motivacionais, comportamentais, cognitivos e psicossomáticos. O bem-estar focaliza-se no estudo das emoções positivas no ambiente laboral, considerando que por meio do trabalho o indivíduo é capaz de desenvolver habilidades, avançando na conquista de suas metas de vida (Paschoal \& Tamayo, 2008).

Diante disto, o presente artigo tem como propósito central pesquisar quais seriam os impactos do assédio moral (AM) no trabalho no bem-estar (BE) no trabalho. Como o assédio moral repercute no bem-estar no traba1ho? Apesar dos dois conceitos AM e BE partirem de diferentes visões teóricas, considera-se relevante investigar uma possível associação entre os mesmos. Para tanto, tem-se como objetivo investigar o quanto o assédio moral influencia no bem-estar no trabalho em estudantes universitários que trabalham e quais atos negativos podem ser preditores da diminuição deste bem-estar. Justifica-se a escolha por esse grupo de trabalhadores levando-se em consideração que, quanto maior o nível educacional do trabalhador, maior a sua expectativa quanto ao tratamento que será recebido no ambiente de trabalho, a sua sensibilidade a incidentes contra a dignidade e a sua disposição para relatar essa visão em questionários (Health and Safety Authority [HSA], 2001).

\section{ASSÉDIO MORAL}

A origem dos estudos sobre a hostilidade no ambiente de trabalho, do ponto de vista organizacional, é atribuída ao psicólogo alemão Henz Leymann (1996), responsável pela introdução do termo mobbing (derivado de " $m o b$ ", horda, bando ou plebe, referenciando-se a uma conduta agressiva, rústica) que se tornou popular na Europa nas décadas de 80 e 90, do século passado. No Brasil a nomenclatura adotada foi Assédio Moral (AM). O fenômeno surgiu inspirado na pesquisa realizado por Marie-France Hirigoyen (1998), na França, cuja tradução foi publicada, em 2000, no Brasil, sob o título: "Assédio moral: a violência perversa no cotidia- no".

Ainda não existe uma definição precisa para o assédio moral na legislação trabalhista, mas, na literatura científica, o assunto configura-se como sendo uma conduta abusiva e sistemática dentro das organizações, acontecendo de forma gradativa. Consiste em uma série de humilhações, perseguições e agressões simultâneas, com o propósito de desestabilizar a vítima emocionalmente (Freitas, 2001; Barreto, 2003; Hirigoyen, 2002, 2005; Guimarães \& Rimoli, 2006; Silva e cols., 2011). $\mathrm{O}$ assédio moral pode envolver duas grandes perspectivas: a do assédio pessoal, relacionado às questões de relações interpessoais; e a do assédio organizacional, associado a demandas do contexto, processo e da gestão do trabalho (Soboll, 2008).

$\mathrm{O}$ assédio moral pode iniciar com pouca intensidade, algo que parece inofensivo, e muitas pessoas não dão importância aos ataques. Entretanto, depois de algum tempo, ele tende a ganhar força e a vítima acaba sofrendo cada vez mais humilhações (Heloani, 2008). É caracterizado pela intencionalidade, sendo que a vítima sofre desqualificação com o intuito de fragilizá-la para que perca o seu poder (Heloani, 2008; Ferreira, 2008).

Para Jacoby e cols. (2009), a sutileza de muitas ações abusivas que caracterizam o assédio moral dificulta a reunião de provas e a mensuração dos fatos para confirmação do mesmo, uma vez que as agressões ocorrem de uma maneira global. Esses autores encontraram em seu estudo que a deterioração progressiva do ambiente de trabalho tem reflexos na vida pessoal e financeira do trabalhador, bem como na sua saúde física e psicológica. As vítimas de assédio moral que participaram deste estudo tinham, em seus perfis, conhecimento, competência, honestidade, dinamismo, ética e atitudes que lhes conferiam crédito e admiração em seus locais de trabalho. Motivos que podem ter sido fundamentais para serem escolhidas como vítimas, uma vez que a inveja apareceu como possível justificativa para que os assediadores tentassem desestabilizar suas vítimas e afastá-las do ambiente de trabalho.

Uma pesquisa realizada com 598 trabalhadores bancários de Porto Alegre e Região Metropolitana constatou diversas doenças relacionadas ao trabalho: distúrbios osteomusculares, estresse, depressão, ansiedade/pânico, gastrite/úlcera, hipertensão ou doenças cardiovasculares, doenças psicossomáticas e dores de cabeça (Amazarray, 2010). Em outra pesquisa com 870 participantes, $100 \%$ dos homens assediados já haviam pensado em suicídio e 18,3\% chegaram a tentá-lo. 
Além disso, $63 \%$ passaram a beber demasiadamente. No caso das mulheres, $16,2 \%$ das vítimas de violência psicológica no ambiente de trabalho indicaram ter pensamentos suicidas e $100 \%$ passaram a ter crises de choro. Esses resultados indicam que ambos os sexos referiram que o AM traz consequências emocionais para a sua vida, mas manifestadas de forma diferente (Barreto, 2003).

Dentre os aspectos que auxiliam o trabalhador a superar a situação de assédio moral destaca-se o apoio social, concebido como auxílio proporcionado por colegas, superiores e pela atuação da empresa no enfrentamento do assédio moral (Amazarray, 2010). É importante o assediado resistir e não se deixar abater. A conversa com os amigos na empresa e com a família, dividindo as angústias e trocando informações sobre medidas a tomar, pode ser uma boa saída para ajudar a superar a situação de assédio moral, além de fortalecer os laços com investimento no companheirismo, na amizade, na sinceridade entre amigos e em relações afetivas (baseadas na confiança) que permitam o assediado falar o que sente (Jacoby e cols., 2009).

É importante que as organizações deem o exemplo por meio de ações éticas e transparentes, profissionais conscientes e métodos de gestão que não aceitem violar a ética e a moral. Organizações sólidas e sadias não dão lugar para o assédio moral (Hirigoyen, 2002).

\section{BEM-ESTAR NO TRABALHO}

O bem-estar no trabalho é um fenômeno amplo e abrange diversos conceitos, envolvendo questões da organização, do direito dos trabalhadores e aspectos subjetivos que compõem a dimensão de bem-estar. As transformações ocorridas no mundo do trabalho, ao longo dos anos, acabaram afetando o bem-estar no ambiente laboral (Akutsu, 2008).

Os estudiosos envolvidos com o conceito de bemestar no campo científico da psicologia buscam compreender os fatores psicológicos que integram uma vida saudável. Para Albuquerque e Tróccoli (2004), o bemestar refere-se ao estudo científico da felicidade. Neste contexto, há uma divisão em dois grupos: do bem-estar subjetivo e do bem-estar psicológico, sendo a principal diferença entre elas residente na concepção de felicidade.

O bem-estar subjetivo compreende a experiência de prazer em relação ao desprazer, realizando julgamentos sobre os elementos positivos e negativos da vida (Ryan \& Deci, 2001). Existe uma compreensão do bem-estar como um fenômeno amplo, em que são consideradas as respostas emocionais do indivíduo e os julgamentos globais sobre a satisfação com a vida. Engloba três dimensões: o afeto positivo (sentimento transitório como um estado de alerta, de entusiasmo e de atividade), o afeto negativo (sentimento transitório que contenha emoções desagradáveis como ansiedade, depressão, agitação, aborrecimento, pessimismo) e a satisfação com a vida (julgamento cognitivo, incluindo circunstâncias da vida da pessoa e os padrões escolhidos por ela) (Albuquerque \& Tróccoli, 2004). O bem-estar subjetivo pode ser considerado como um estado afetivo, no qual a vivência positiva se sobressai perante a negativa.

Já na visão do bem-estar psicológico todo o comportamento objetiva a felicidade, indo além da visão do bem-estar subjetivo. Considera-se também a realização do potencial e das metas fundamentais de vida, sendo centrado na experiência de sentimentos de expressividade pessoal e de autorrealização (Paschoal \& Tamayo, 2008). Visto, desta forma, como um avanço de potenciais e dos propósitos de vida, superando o estado afetivo do indivíduo.

A questão do bem-estar no trabalho deve ser considerada bastante relevante, uma vez que o trabalhador passa uma parte significativa de sua vida no ambiente laboral (Tamayo, 2004). Na busca de uma definição para o bem-estar no ambiente de trabalho, Siqueira e Padovam (2008) propõem a conexão de três componentes: satisfação no trabalho (vínculo positivo com o trabalho e as satisfações que se obtém nas relações de trabalho, com o salário e com a empresa), envolvimento com o trabalho (experiência positiva com o trabalho, incluindo desafios e uso de habilidades, a fim de atingir metas estabelecidas e obter feedback claro e imediato) e comprometimento organizacional afetivo (ligação positiva entre empregado e empregador, proporcionando boas e prazerosas vivências, estando em conexão com a empresa e sua filosofia, com apego e dedicação).

No que tange ao bem-estar no ambiente de trabalho, pouco tem sido tratado, prevalecendo estudos que versam sobre aspectos negativos como estresse, Burnout, entre outros (Siqueira \& Padovam, 2008). Como descreve Amazarray (2010), estudos que preconizam fatores de proteção, objetivando a compreensão de elementos que envolvem a saúde e o bem-estar no trabalho são de extrema relevância para trabalhar a dimensão positiva na relação saúde/trabalho. Ainda conforme esta autora, além de aprimorar a compreensão da dinâmica do funcionamento das relações saúde e 
trabalho, investigações com este propósito permitem subsidiar a promoção de condições de trabalho que promovam prazer e saúde dos sujeitos.

Camargo e Neves (2004) assinalam a importância de pesquisas que abarquem o tema da saúde mental no mundo do trabalho sob o viés positivo, pois a maior parte dos estudos tem focalizado as demandas relacionadas ao sofrimento mental no trabalho, suas causas e consequências. Isto se deve às altas incidências e prevalências de sofrimento no ambiente laboral, acarretando prejuízos ao trabalhador, repercutindo também em perdas econômicas para o empregador, entre outras implicações de nível macro-econômico.

\section{MÉTODO}

Diante do objetivo de investigar e explicar a relação do assédio moral em estudantes universitários que trabalham e o bem-estar no trabalho fez-se a opção pela realização de um estudo quantitativo, de caráter correlacional e explicativo.

\section{Amostra}

Participaram deste estudo 457 estudantes trabalhadores matriculados em uma faculdade particular situada na região metropolitana de Porto Alegre/RS, de ambos os sexos, empregados em empresas de diferentes ramos.

O cálculo amostral, com índice de confiança de 95\% e taxa de erro 5\%, previa o número de 362 participantes, tomando-se a população de 6.000 estudantes para detectar pequenos a médios effect sizes, considerando o nível de significância de $\mathrm{p}=0,05$ e uma chance de não cometer erro $\beta$ de $90 \%$, na maioria dos delineamentos. Como critério de inclusão foi considerado o fato dos estudantes estarem trabalhando há, pelo menos, seis meses. A maior parte da população do estudo é constituída por mulheres $(69,1 \%)$, solteiros $(68,7 \%)$, que pertenciam ao nível operacional $(59,1 \%)$ e com uma jornada de trabalho entre 40 e 44 horas semanais $(42,2 \%)$.

No que diz respeito à descrição das variáveis intervalares, a idade dos participantes variou de 17 a 64 anos, com idade média de 26,02 anos; o tempo de trabalho na empresa variou de seis meses a 39 anos $(m=4,27 ; S D=5,05)$ e o tempo na função atual variou de um mês a 27 anos $(m=3,19, S D=3,69)$.

A grande maioria dos participantes $(96,2 \%)$ não era membro do sindicato ou associação dos empregados ou representante dos funcionários e trabalhava no turno diurno $(92,4 \%)$. Poucos trabalhadores relataram história de acidente ou doença de relacionada ao trabalho $(3,9 \%)$, que variaram entre: acidente de percurso, corte de dedo, problemas de coluna, crise de estresse, tendinite, alergia, entre outros. Em relação ao apoio recebido frente a uma situação adversa no trabalho, $97,8 \%$ dos participantes relataram procurar algum tipo de auxílio, dentre eles: $34,4 \%$ buscam o setor de recursos humanos ou o serviço especializado em engenharia de segurança e medicina do trabalho, $32,6 \%$ buscam apoio na família, $12,7 \%$ na chefia, 5,5 no sindicato e os demais em amigos, serviços de saúde e delegacia regional do trabalho.

\section{Instrumentos}

Foram utilizados três instrumentos autoaplicáveis: um Questionário biossocial, demográfico e laboral, o Questionário de Atos Negativos e as Medidas de Bemestar no Trabalho, descritos a seguir.

Questionário biossocial, demográfico e laboral: para este estudo, foi elaborado um instrumento composto por questões biossociais, demográficas e laborais, autoaplicável, que visou obter informações sobre idade, gênero, estado civil, escolaridade, número de filhos, setor que trabalha na empresa, função desempenhada, tempo de trabalho, entre outras. Tais variáveis foram utilizadas para descrever os participantes, a fim de caracterizar a amostra, além de serem utilizadas em comparações relacionadas às variáveis dependentes.

Questionário de Atos Negativos - QAN: este instrumento autoaplicável (Cozby, 2009) tem sido bastante usado na Europa, onde é conhecido como Negative Acts Questionnaire (NAQ). Foi elaborado na Noruega, por Einarsen, Raknes, Matthiesen e Hellesoy (1994), e revisado por Einarsen e Raknes (1997, apud Einarsen e Hoel, 2001). A primeira parte do instrumento avalia a exposição a atos negativos potenciais de assédio moral, durante os últimos 6 meses, numa escala Likert de cinco pontos (nunca, de vez em quando, mensalmente, semanalmente e diariamente). São descrições de atos negativos que não mencionam o termo assédio moral, referindo-se a comportamentos diretos (agressão verbal, intimidação, etc) e indiretos (isolamento social, pressão, etc). Na segunda parte, é proposta uma definição de assédio moral no trabalho e solicitado que o(a) respondente indique se foi exposto ao fenômeno nos últimos seis meses, seguida de perguntas sobre duração e características do evento. Na sequência, são feitas duas perguntas que investigam se o (a) participante já havia praticado assédio moral no trabalho nos últimos seis meses e nos últimos cinco anos. 
Estudos com diferentes amostras, segundo Einarsen e Hoel (2001), mostraram alta consistência interna com valores de Alpha de Cronbach variando de 0,83 a 0,92. Em pesquisa que validou instrumento no Brasil (Maciel \& Gonçalves, 2008) foi encontrado um Alpha de 0,90, para a versão reduzida com 22 itens. Amazarray (2010) em seus estudos com bancários encontrou Alpha de Cronbach de 0,94, também com a versão curta. No presente estudo, foi utilizada a versão longa e o Alpha de Crombach encontrado foi de 0,92.

A partir do QAN, foi criada uma variável contínua, QAN Total, que mediu o assédio moral no trabalho. A mesma foi calculada pela pontuação média dos 29 itens (somou-se o escore no QAN e dividiu-se pelo número total de itens).

Medidas de Bem-estar no Trabalho, compostas por três escalas:

1) Escala de Satisfação no Trabalho: construída e validada, no Brasil, por Siqueira (1995). Trata-se de uma escala multifatorial, que tem o objetivo de medir o grau de contentamento dos trabalhadores diante de cinco dimensões de seu trabalho. Foi utilizada a versão reduzida, composta por 15 itens, com três itens cada fator: colegas (Alpha de Conbach 0,81), chefia (Alpha de Conbach 0,84), salário (Alpha de Conbach 0,90), promoções (Alpha de Conbach 0,81) e natureza das tarefas (Alpha de Conbach 0,77).

Neste estudo, foram encontrados os seguintes valores de Alpha de Cronbach: colegas $(0,49)$, chefia $(0,89)$, salário $(0,90)$, promoções $(0,87)$ e natureza das tarefas $(0,77)$. Foram também calculadas as médias de cada fator, além do escore médio total da satisfação, através do somatório dos cinco fatores. A interpretação dos resultados deve considerar que quanto maior o valor do escore médio, maior o grau de satisfação no trabalho (Siqueira, 2008b).

2) Escala de Envolvimento com o Trabalho: o objetivo desta escala é avaliar o quanto o trabalho consegue promover satisfações para o indivíduo, absorvê-lo enquanto realiza tarefas e ser importante para a sua vida. Esta escala foi validada no Brasil por Siqueira (1995), que reduziu a escala para cinco itens, com Alpha de Cronbach 0,78. No presente estudo encontrou-se Alpha de Cronbach de 0,82. As respostas são apresentadas em uma escala Likert de 7 pontos, variando de discordo totalmente a concordo totalmente. Foi utilizado o escore médio, como variável contínua. Na interpretação dos dados deve-se considerar que quanto maior o valor do escore médio, maior o grau de envolvimento com o tra- balho (Siqueira, 2008a).

3) Escala de Comprometimento Organizacional Afetivo: o objetivo desta escala é avaliar a intensidade com que os trabalhadores mantém sentimentos positivos diante da organização em que trabalham. Esta escala foi elaborada e validada por Siqueira (1995), que obteve Alpha de Cronbach 0,93 na forma reduzida. No presente estudo, foi utilizada esta versão e encontrou-se Alpha de Cronbach de 0,95. Trata-se de um Instrumento composto por cinco itens em escala tipo Likert de 5 pontos (nada, pouco, mais ou menos, muito e extremamente). Utilizou-se o escore médio, como variável contínua. Para interpretação, quanto maior o valor de escore médio, mais forte era o compromisso afetivo do participante com a organização (Bastos, Siqueira, Medeiros \& Menezes, 2008).

\section{Procedimentos de coleta de dados}

O estudo foi autorizado pelo Comitê de Ética da Universidade do Vale do Rio dos Sinos (Resolução 050/2011, aprovado em 19/05/2011). Os participantes assinaram um Termo de Consentimento Livre e Esclarecido, no qual foi assegurada a preservação de sua identidade e sigilo das informações prestadas. A coleta de dados foi realizada dentro das salas de aula da faculdade, em papel, em grupo, durante as aulas, no período de agosto a outubro de 2011. Antes da coleta, foi realizado um estudo piloto, para verificar a adequação dos enunciados e o tempo necessário para responder.

\section{Procedimentos de análise de dados}

Os resultados dos instrumentos foram levantados e tabulados em um banco de dados. Foi realizada a categorização das respostas abertas (raça, religião, tipo de acidente ou doença do trabalho e busca de apoio). Essa categorização foi feita segundo o método de análise de conteúdo quantitativa (Bardin, 1977/2007), com levantamento de frequências, realizando a contagem das unidades de análise de todos os questionários.

Foi realizada uma correlação de Pearson, para avaliar associação entre o QAN e as medidas de bem-estar no trabalho. Posteriormente, foi realizada análise de regressão linear múltipla para identificar o poder preditivo das questões do QAN em relação às medidas de bem-estar no trabalho, adotando-se nível de significância de $5 \%$. Foram realizadas três análises de regressão múltipla pelo método stepwise, cada uma delas utilizou como variável dependente uma das escalas da medida de bem-estar no trabalho: Escala de Envolvimento com o Trabalho - EET, Escala de Satisfação com o Trabalho 
- EST e Escala de Comprometimento Organizacional Afetivo - ECOA, e como variáveis independentes, o conjunto de variáveis biossocial, demográficas, laborais e o conjunto de questões do QAN.

\section{RESULTADOS}

$\mathrm{O}$ assédio moral foi medido através do Questionário de Atos Negativos - QAN e o bem-estar no trabalho foi mensurado pelas Medidas de Bem-Estar no Trabalho: Escala de Envolvimento com o Trabalho, Escala de Comprometimento com o Trabalho e Escala de Satisfação com o Trabalho. As medidas de tendência central e de dispersão do Assédio Moral e do Bem-estar no Trabalho estão apresentadas na tabela 01 . Na Escala de Satisfação no Trabalho, a média mais alta foi em relação à chefia, seguida pelo contentamento em relação aos colegas.

Tabela 1

Medidas e Desvios-padrão do QAN Total das Medidas de Bem-estar no Trabalho

\begin{tabular}{lccc}
\hline Instrumento/Escala & $\boldsymbol{M}$ & $\boldsymbol{S D}$ & $\mathbf{N}$ \\
\hline QAN Total & 1,34 & 0,38 & 454 \\
Envolvimento com o trabalho & 3,62 & 1,35 & 437 \\
Comprometimento organizacional afetivo & 3,54 & 0,89 & 439 \\
Satisfação - colegas & 4,92 & 1,54 & 441 \\
Satisfação - chefia & 4,94 & 1,42 & 441 \\
Satisfação - salário & 3,83 & 1,52 & 439 \\
Satisfação - promoções & 3,98 & 1,51 & 440 \\
Satisfação - natureza do trabalho & 4,58 & 1,13 & 440 \\
\hline
\end{tabular}

Verificaram-se algumas correlações negativas significativas do fenômeno do assédio moral com as variáveis do bem-estar no trabalho. $\mathrm{O}$ assédio moral associou-se negativamente com as variáveis de bem-es- tar no trabalho, apresentando significância $(\mathrm{p}<0,05)$, indicando que quanto maior é a presença de atos negativos no trabalho menor é a satisfação e o comprometimento no trabalho. Cabe ressaltar, no entanto, que a correlação entre o assédio moral e o envolvimento no trabalho pode ser classificada como uma associação quase insignificante $(\mathrm{r}=-0,10)$. Tais relações podem ser visualizadas na tabela 02 .

\section{Tabela 2}

Correlações entre QAN total e as Medidas de Bem-estar no Trabalho

\begin{tabular}{lcccc}
\hline & QAN Total & EET & EST & ECOA \\
\hline QAN Total & 1,00 &,$- 100^{*}$ &,$- 385^{* *}$ &,$- 429^{* *}$ \\
EET &,$- 100^{*}$ & 1,00 &, $506^{* *}$ &, $456^{* *}$ \\
EST &,$- 385^{* *}$ &, $506^{* *}$ & 1,00 &, $667^{* *}$ \\
ECOA &,$- 429^{* *}$ &, $456^{* *}$ &, $667^{* *}$ & 1,00 \\
\hline Nota: ${ }^{*}<<0,05 e^{* *} p<0.001$ & & &
\end{tabular}

Partindo das correlações encontradas, realizou-se uma análise de regressão linear múltipla para identificar quais são as variáveis preditoras e a contribuição de cada uma delas para explicar a diminuição do bem-estar no trabalho.

Os resultados obtidos na dimensão da Escala de Satisfação no Trabalho apontam para um modelo preditor composto pelas variáveis: pressão para não reclamar um direito, ser ignorado/excluído, ameaças de violência/abuso físico, realizar tarefas que não fazem parte do trabalho, tentativas de encontrar erros nas tarefas e executar trabalho abaixo do nível de competência (Tabela 03). Estes fatores, conjuntamente, explicam 23,4\% da diminuição da Satisfação no Trabalho. A variável com maior poder explicativo refere-se à "percepção sobre pressão para não reclamar um direito que é seu" com $9 \%$ de variância.

Tabela 3

Variáveis preditoras das dimensões de Satisfação no Trabalho

\begin{tabular}{llllll}
\hline \multicolumn{1}{c}{ Variáveis } & $\mathbf{R}$ & $\mathbf{R 2}$ & $\mathbf{B e t a}$ & $\mathbf{t}$ & $\mathbf{P}$ \\
\hline 1. Pressão para não reclamar um direito &, 301 &, 090 &,- 157 & $-3,175$ &, 002 \\
2. Ignorado/excluído &, 370 &, 137 &,- 212 & $-4,543$ &, 000 \\
3. Ameaças de violência/abuso físico &, 413 &, 171 &, 201 & 4,478 &, 000 \\
4. Tarefas que não fazem parte do trabalho &, 453 &, 206 &,- 158 & $-3,521$ &, 000 \\
5. Tentativas de encontrar erros nas tarefas &, 474 &, 224 &,- 135 & $-2,870$ &, 004 \\
6. Trabalho abaixo do nível de competência &, 484 &, 234 &,- 112 & $-2,341$ &, 020 \\
\hline
\end{tabular}


Com relação ao Comprometimento Organizacional Afetivo, o modelo final explicou $26,4 \%$ da variabilidade, sendo detectadas como preditoras as variáveis: falta de informações que afeta o trabalho, ser ignorado/excluído, pressão para não reclamar um direito, realizar tarefas que não fazem parte do trabalho, receber sinais para pedir demissão, mensagens/telefonemas contendo insultos, ofensas em relação raça ou etnia, pegadinhas, boatos/rumores e ofensas sobre atitudes e vida privada (Tabela 04). A variável com maior poder explicativo foi a que avaliou a falta de informações que afetam o trabalho, com $12 \%$ da variância.

Os resultados evidenciaram relação negativa com as variáveis do modelo explicativo revelando que estes atos negativos diminuem a satisfação no trabalho. Não foi realizada uma regressão linear múltipla para a Escala de Envolvimento com o Trabalho, devido ao fato dela não ter se correlacionado significativamente com o assédio moral.

Tabela 4

Variáveis preditoras das dimensões de Comprometimento Organizacional Afetivo

\begin{tabular}{lccccc}
\multicolumn{1}{c}{ Variáveis } & $\mathbf{R}$ & $\mathbf{R 2}$ & Beta & $\mathbf{t}$ & $\mathbf{P}$ \\
\hline 1. Falta de informações que afeta o trabalho &, 348 &, 121 &,- 209 & $-4,160$ &, 000 \\
2. Ignorado/excluído &, 413 &, 171 &,- 184 & $-3,553$ &, 000 \\
3. Pressão para não reclamar um direito &, 443 &, 196 &,- 122 & $-2,452$ &, 015 \\
4. Tarefas que não fazem parte do trabalho &, 461 &, 213 &,-128 & $-2,918$ &, 004 \\
5. Sinais para pedir demissão &, 471 &, 222 &,- 093 & $-1,894$ &, 059 \\
6. Mensagens/telefonemas contendo insultos &, 480 &, 231 &, 139 & 2,923 &, 004 \\
7. Ofensas em relação raça ou etnia &, 488 &, 239 &,- 096 & $-2,154$ &, 032 \\
8. Pegadinhas &, 496 &, 246 &,- 087 & $-1,783$ &, 075 \\
9. Boatos/rumores &, 505 &, 255 &, 143 & 2,800 &, 005 \\
10. Ofensas sobre atitudes e vida privada &, 513 &, 264 &,- 111 & $-2,239$ &, 026 \\
\hline
\end{tabular}

\section{DISCUSSÃO}

O resultado da análise de correlação possibilitou que se conhecessem os padrões de inter-relação entre o assédio moral e as medidas de bem-estar no trabalho. Houve correlação significativa $(p<0,05)$ e negativa entre as medidas de bem-estar no trabalho (comprometimento organizacional afetivo e a satisfação no trabalho) com o assédio moral. Conforme diversos autores, o assédio moral é responsável pela deterioração do ambiente laboral, implicando na desmotivação, insatisfação com o trabalho, diminuição do comprometimento organizacional e da produtividade (Leymann, 1996; Hirigoyen, 2002; Jacoby et al., 2009), fatores estes que estão relacionados com as questões de bem-estar no trabalho (Paschoal \& Tamayo, 2008; Dessen \& Paz, 2010).

A partir das associações encontradas, justificou-se a realização de uma análise de regressão para verificar quais as variáveis preditoras de bem-estar no trabalho. As variáveis relacionadas com a satisfação e com o comprometimento organizacional afetivo tiveram relação inversa com o assédio moral. No modelo de regres- são os preditores da satisfação no trabalho apresentaram poder explicativo de $23,4 \%$, percentual considerado satisfatório, na área de ciências humanas, levando em conta tratar-se de um fenômeno extremamente subjetivo. As variáveis preditoras, segundo ordem de poder explicativo, foram: pressão para não reclamar um direito, ser ignorado/excluído, ameaças de violência/abuso físico, realizar tarefas que não fazem parte do trabalho, tentativas de encontrar erros nas tarefas, executar trabalho abaixo do nível de competência (Tabela 04).

A satisfação no trabalho está relacionada ao vínculo positivo com o trabalho e as satisfações que se obtém nas relações de trabalho com a chefia, com os colegas, com o salário, com as oportunidades de promoção dentro da empresa e com as tarefas realizadas (Siqueira \& Padovam, 2008). Considerando as variáveis que neste estudo explicam a diminuição da satisfação no trabalho, observa-se que são prioritariamente as que indicam comprometimento nas relações com a chefia e com colegas. Estudos anteriores (Padovam, 2005; Siqueira, 2003) também apontam os fatores sócio organizacio- 
nais como os mais importantes para compreender as variações da satisfação no trabalho, mostrando que as variáveis preditoras encontradas estão em consonância com a menor satisfação no ambiente laboral.

A ocorrência de atos negativos relacionados ao assédio moral pode causar insatisfação com o superior hierárquico evidenciando a deterioração das relações sociais no ambiente laboral. Esses dados indicam que mesmo que o assédio moral possa ser visto, muitas vezes, como uma prática institucionalizada ou banalizada (Dejours, 2001), acaba comprometendo as relações sociais no trabalho, que ficam afetadas diante da presença de atos negativos. $\mathrm{O}$ estilo de liderança tem sido apontado em estudos como fator importante para o entendimento do assédio moral, mostrando que tanto lideranças rígidas como inexistentes atrapalham a resolução de conflitos e, consequentemente, elevam o nível de estresse, beneficiando o surgimento de práticas de violência no ambiente laboral (Amazaray, 2010).

Da mesma forma, instituições que não estão tão preocupadas com a ética, ou dissimuladas por práticas gerenciais inadequadas (Hirigoyen, 2002) - nas quais há deterioração das condições de trabalho, isolamento e recusa da comunicação, atentado contra a dignidade e violência verbal, física e sexual - podem trazer como consequência uma diminuição do bem-estar no trabalho. Estas práticas, comuns em situações de assédio moral, levam a diminuição da satisfação no trabalho. A queda da produtividade também é mencionada em alguns estudos (Einarsen, 2000; Silva, Oliveira, \& Zambroni-de-Souza, 2011) como um efeito do assédio moral e como um fator relacionado à insatisfação no trabalho (Siqueira, 2008b).

A partir deste estudo, pode-se considerar que práticas condizentes com o assédio moral organizacional podem ser responsáveis pela diminuição da satisfação no trabalho. Conforme Gosdal e Soboll (2009), o assédio moral organizacional faz parte da estratégia de gestão de muitas empresas, que buscam maior produtividade e alcance de metas, sendo conivente e incentivando atos negativos. A variável "pressão para não reclamar um direito" está fortemente ligada a este tipo de assédio, que objetiva destruir a subjetividade do trabalhador.

Metade das variáveis preditoras da satisfação no trabalho está relacionada com tarefas (que não fazem parte do trabalho, busca de erro, abaixo da competência), reforçando a ideia que o assédio moral organizacional é o responsável pala diminuição na satisfação. Essas tarefas vêm exigindo, cada vez mais, polivalência, absorção de atividades que não eram suas e maior controle e supervisão do trabalhador (Cimbalista, 2006).

O modelo de regressão para os preditores do comprometimento organizacional afetivo apresentou poder explicativo de $26,4 \%$, percentual também considerado satisfatório. As variáveis preditoras, segundo ordem de poder explicativo, foram: falta de informações que afetam o trabalho, ser ignorado/excluído, pressão para não reclamar um direito, realizar tarefas que não fazem parte do trabalho, receber sinais para pedir demissão, mensagens/telefonemas contendo insultos, ofensas em relação raça ou etnia, pegadinhas, boatos/rumores e ofensas sobre atitudes e vida privada (Tabela 04).

O comprometimento organizacional afetivo está relacionado com a ligação positiva entre empregado e empregador, proporcionando boas e prazerosas vivências, estando em conexão com a empresa (Siqueira \& Padovam, 2008). A literatura científica assinala que os elementos relacionados com as vivências no trabalho possuem importância sobre o bem-estar no trabalho, como clima social, percepção de justiça e suporte organizacional (Mourão, 2009, Paschoal, 2008). Neste sentido, foi interessante observar que o modelo de regressão incluiu diversas variáveis do assédio moral entre as preditoras da diminuição do bem-estar no trabalho. Ou seja, os atos negativos apresentados afetam a relação trabalhador-trabalho e causam, consequentemente, uma degradação do local de trabalho e das relações sociais ali estabelecidas.

É possível interpretar que menores níveis de bemestar no trabalho são decorrentes das situações laborais difíceis como: pressão para não reclamar um direito, ser ignorado/excluído e realizar tarefas que não fazem parte do trabalho, preditores que apareceram em duas dimensões das medidas de bem-estar no trabalho: a satisfação no trabalho e o comprometimento organizacional afetivo.

A única dimensão do bem-estar no trabalho que não se correlacionou com o assédio moral foi o envolvimento com o trabalho, a qual se refere ao valor atribuído ao trabalho na vida da pessoa. Talvez essa dimensão não seja afetada significativamente nas situações de assédio moral pelo fato das vítimas, apesar de terem vivenciado situações de violência, continuarem realizando suas tarefas e dando importância ao trabalho. Pessoas que apresentam conhecimento, competência e ética (Jacoby et al, 2009) buscam atingir as metas da organização, muitas vezes, não percebendo os atos ne- 
gativos, ou não dando gravidade a eles, primando pela realização dos deveres impostos pelo seu trabalho e, desta forma, buscando atingir os resultados de produtividade esperados no mundo do trabalho atual.

\section{CONSIDERAÇÕES FINAIS}

O objetivo do presente artigo foi investigar a relação entre o assédio moral e o bem-estar no trabalho. Como o assédio moral repercute no bem-estar no trabalho? O quanto o assédio moral influencia no bem-estar no trabalho e quais os atos negativos que poderiam ser preditores da diminuição deste bem-estar.

Os resultados do estudo mostraram correlação entre o assédio moral e duas medidas de bem-estar no trabalho (a satisfação no trabalho e o comprometimento organizacional afetivo), sugerindo que o assédio moral causa uma diminuição do bem-estar no ambiente laboral. Nesse sentido, o assédio moral mostrou-se responsável pela diminuição da satisfação e do comprometimento dentro das organizações, propiciando um ambiente laboral desfavorável à saúde e ao bem-estar do trabalhador.

Na satisfação no trabalho as variáveis preditoras observadas confirmam que o assédio moral afeta de forma negativa o vínculo positivo com o trabalho e com as relações sócio profissionais. Visto que, entre os fatores relacionados com a satisfação estão o enriquecimento do trabalho e o aumento do conhecimento e das habilidades relacionadas às tarefas, fatores apontados como não atendidos nas empresas dos participantes do estudo. Neste caso, os trabalhadores estudados são aqueles que buscam um aprimoramento de sua qualificação profissional, através de curso superior e, desta forma, visam um maior reconhecimento pelo trabalho que desenvolvem e a realização de tarefas que sejam coniventes com o seu nível educacional.

O fato de metade das variáveis preditoras estarem relacionadas às tarefas indica a presença do assédio moral organizacional, com práticas de violência como parte das estratégias de gestão da empresa, buscando controlar a subjetividade do trabalhador e forçando-o a ser polivalente e absorver tarefas que antes não eram suas, com um controle excessivo e uma pressão para não cometer erros e produzir cada vez mais.

As variáveis encontradas como preditoras do comprometimento organizacional afetivo no estudo indicam a degradação do vínculo do trabalhador com a organização. Um menor comprometimento organizacional mostra, também, uma organização focada na heterogestão e com hierarquia mais rígida (Tomas et al., 2000), confirmando o perfil de empresas que são coniventes com situações de assédio moral.

Não foram localizados na literatura resultados específicos relativos ao assédio moral e o bem-estar que pudessem confirmar os resultados deste estudo. Entretanto, verificou-se que as consequências do assédio moral afetam diretamente a saúde e o bem-estar do trabalhador que, diante das situações de violência, tem a sua satisfação com o trabalho e o comprometimento organizacional diminuídos.

A maior satisfação no trabalho está ligada a ter emoções positivas no ambiente laboral e perceber que a organização e seus gestores demostram interesse e fornecem suporte propicia o seu aumento. A existência de regras definidas, centradas em padrões morais e éticos e aplicáveis a todos da organização, e o fato das pessoas serem reconhecidas e valorizadas por seus feitos e sua competência possibilitam a elevação dos níveis de bem-estar no trabalho.

Este estudo não teve pretensão de esgotar as possibilidades de análise, foi uma pesquisa inicial, existindo espaço para uma expansão dos fatores estudados. Para estudos futuros, sugere-se a realização de pesquisas longitudinais com trabalhadores que sofreram assédio moral e que tiveram uma diminuição do bem-estar no trabalho, que poderão ser úteis para investigar aspectos como as estratégias de enfrentamento do fenômeno, as repercussões na saúde do trabalhador, em longo prazo, e o quanto a empresa é afetada com a ocorrência de atos negativos.

\section{REFERÊNCIAS}

Albuquerque, A. S.; Tróccoli, B. T. (2004). Desenvolvimento de uma escala de bem-estar subjetivo. Psicologia: Teoria e Pesquisa, 20, 153-164.

Akutso, R.C.C.A. (2008). Valores e bem-estar dos nutricionistas brasileiros. Tese de Doutorado, Universidade de Brasília, Brasília.

Amazarray, M. R. (2010). Violência psicológica e assédio moral no trabalho enquanto expressões de estratégia de gestão. Tese de Doutorado em Psicologia, Universidade Federal do Rio Grande do Sul, Porto Alegre.

Antunes, R. (2009). Os sentidos do trabalho: ensaio sobre a afirmação e a negação no trabalho. São Paulo: Boitempo.

Bardin, L. (2007). Análise de Conteúdo. Lisboa: Edições 70. (Original publicado em 1977).

Barreto, M. (2003). Violência, saúde e trabalho: uma jornada de humilhações. São Paulo: EDUC. 
Bastos, A. V. B.; Siqueira, M. M. M.; Medeiros, C. A. F. Menezes, I. G. (2008). Comprometimento organizacional. In M. M. M. Siqueira (Org.), Medidas do comportamento organizacional: ferramentas de diagnóstico e de gestão (pp. 49-95). Porto Alegre: Artes Médicas.

Camargo, D. A.; Neves, S. N. H. (2004). Transtornos mentais, saúde mental e trabalho. L. A. M. Guimarães; S. Grubits (Orgs.), Série Saúde Mental e Trabalho (pp. 2342). São Paulo: Casa do Psicólogo.

Cimbalista, S. Reflexões sobre o trabalho e a subjetividade de trabalhadores resilientes sob o sistema de produção flexível. Revista FAE, 9, 13-28.

Cozby, P. C. (2009). Métodos de pesquisa em ciências do comportamento. São Paulo: Atlas.

Dejours, C. (2001). A Banalização da injustiça social. 4 ed. Rio de Janeiro: Fundação Getúlio Vargas.

Dessen, M.C.; Paz, M.G. (2010). Validação do instrumento de indicadores de bem-estar pessoal nas organizações. Psicologia em Estudo, 5, 409-418.

Eberle, A.D.; Soboll, L. A. P.; Horst, A. C. (2010). Avaliação comparativa de resultados e assédio moral organizacional: concorrência generalizada, individualismo e adoecimento no trabalho. In . A. M. Mendes; A. R. C. Merlo; C. F. Morrone; E. P. Facas (Orgs.), Psicodinâmica e clínica do trabalho: temas, interfaces e casos brasileiros. (pp. 518-535). Curitiba: Juruá.

Einarsen, S. (2000). Harassment and bullying at work: a review of the Scandinavion approach. Agression and violent behavior, 5, 379-401.

Einarsen, S.; Hoel, H. (2001). The Negative Acts Questionnaire: Development, validation and revision of a measure of bullying at work. Proceedings of the $10^{\text {th }}$. European Congress on Work and Organizational Psychology, Prague.

Freitas, M. (2001). Assédio moral e assédio sexual: faces do poder perverso nas organizações. RAE - Revista de Administração de Empresas, 41, 8-19.

Ferreira, J. B. (2008). Violência e assédio moral no trabalho: Patologias da solidão e do silêncio. In L.A.P. Soboll (Orgs.), Violência psicológica e assédio moral no trabalho: Pesquisas brasileiras (pp. 104-134). São Paulo: Casa do Psicólogo.

Gosdal, T.C.; Soboll, L.A.P. (2009). Assédio moral interpessoal e organizacional. São Paulo: LTr.

Guimarães, L. A. M., Rimoli, A. O. (2006). "Mobbing” (Assédio psicológico) no trabalho: uma síndrome psicossocial multidimensional. Psicologia: Teoria e Pesquisa, 22v., 183-192.

Heloani, J. R.(2008). Contribuições da psicologia do trabalho em casos de assédio moral. In L.A.P. Soboll (Org.), Violência psicológica e assédio moral no trabalho: Pesquisas brasileiras (pp. 95-104). São Paulo: Casa do Psicólogo.

Health and Safety Authority. (2001). Report of the task force on the prevention of workplace bullying: Dignity at work - the challenge of workplace bullying. Dublin, Irish: The Stationary Office.
Hirigoyen, M. F. (2002). Mal-estar no trabalho: redefinindo $o$ assédio moral. Rio de Janeiro: Bertrand Brasil.

Hirigoyen, M. F. (2005). Assédio moral: a violência perversa no cotidiano. Rio de Janeiro: Bretand Brasil.

Jacoby, A. R.; Falcke, D.; Lahm, C. R.; Nunes, G. J. (2009). Assédio Moral: uma guerra invisível no contexto empresarial. Revista Mal-Estar e Sujetividade. (IXv., 2n., pp. 619-645). Fortaleza.

Leymann, H. (1996). The contente and development of mobbing at work. European Journal of work and Organizational Psychology, 5, 165-184.

Martins, S. R.; Moraes, R. D.; Lima, S. C. C. (2010). Sofrimento, defesa e patologia: o olhar da psicodinâmica sobre a violência no trabalho. In A. M. Mendes (Org.), Violência no trabalho: perspectivas da psicodinâmica, da ergonomia e da sociologia clínica. (pp. 19-39). São Paulo: Universidade Presbiteriana Mackenzie.

Mendes, A. M. (2007a). Da psicodinâmica à psicopatologia do trabalho. In A. M. Mendes (Org), Psicodinâmica do trabalho: teoria, método e pesquisas (pp. 29-48). São Paulo: Casa do psicólogo.

Mendes, A. M. (2007b). Conflitos de Relacionamento no Trabalho. Palestra proferida no Seminário de Gestão da Ética nas Empresas Estatais.

Monteiro, J. K. (2010). Organização do trabalho e sofrimento psíquico de trabalhadores da saúde. In A. M. Mendes; A. R. C. Merlo; C. F. Morrone; E. P. Facas (Orgs.), Psicodinâmica e clínica do trabalho: temas, interfaces e casos brasileiros. (pp. 335-345). Curitiba: Juruá.

Monteiro, J. K.; Machado, C.(2010). Violência no trabalho em um hospital público. In Mendes, A. M. (Org). Violência no trabalho: perspectivas da psicodinâmica, da ergonomia e da sociologia clínica. (pp. 139-154). São Paulo: Universidade Presbiteriana Mackenzie, 2010.

Mourão, R.G.V. (2009). O impacto da percepção de justiça organizacional no bem-estar do trabalho do trabalhador de uma organização pública. Dissertação de mestrado, Universidade Católica de Brasília, Brasília.

Paschoal, T. (2008). Bem-estar no trabalho: relações com suporte organizacional, prioridades axiológicas e oportunidades de alcance de valores pessoais no trabalho. Tese de doutorado, Universidade de Brasília, Brasília.

Paschoal, T.; Tamayo, A. (2008). Construção e validação da escala de bem-estar no trabalho. Avaliação Psicológica, 7, 11-22.

Ryan, C. D.; Deci, E. L. (2001). On Happiness and human potentials: a review of research on hedonic and eudaimonic well being. Annual Review of Psychology, 52, 141166.

Silva, E.F.; Oliveira, K.K.M.; Zambroni-de-Souza, P.C. (2011). Saúde mental do trabalhador: o assédio moral praticado contra trabalhadores com LER/DORT. Revista Brasileira de Saúde Ocupacional, 36, 56-70.

Siqueira, M. M. M. (1995). Antecedentes de comportamentos de cidadania organizacional: a análise de um modelo pós-cognitivo. Tese de doutorado, Universidade de Brasília. Brasília. 
Siqueira, M. M. M. (2003). Proposição e análise de um modelo para comportamentos de cidadania organizacional. Revista de Administração Contemporânea, 7, 165-185.

Siqueira, M. M. M.; Padovam, V. A. R. (2008). Bases teóricas de bem-estar subjetivo, bem-estar psicológico e bemestar no trabalho. Psicologia: Teoria e Pesquisa, 24, 201209.

Siqueira, M. M. M. (2008a). Envolvimento com o trabalho. In M.M.M. Siqueira (Org.), Medidas do comportamento organizacional: ferramentas de diagnóstico e de gestão (pp. 139-143). Porto Alegre: Artes Médicas.

Siqueira, M. M. M. (2008b). Satisfação no trabalho. In M.M.M. Siqueira (Org.), Medidas do comportamento organizacional: ferramentas de diagnóstico e de gestão (pp. 265-274). Porto Alegre: Artes Médicas.
Soboll, L. A. P. (2008). Assédio moral organizacional: uma análise da organização do trabalho. São Paulo: Casa do Psicólogo.

Tamayo, A. (2004). Introdução. In A. Tamayo (Org.), Cultura e saúde nas organizações (pp. 11-16). Porto Alegre: Artmed.

Tomas, E.; Remesseiro, A.; Codo, J. (2000). Psicología del trabajo, de las organizaciones y de los recursos humanos. Espanha: Biblioteca Nueva Editora.

Recebido em: 24/10/2012 Primeira decisão editorial em: 26/01/2015 Aceito em: 08/12/2016 